\title{
A Knowledge-Based System for Life Insurance Underwriting
}

\author{
Mutai K. Joram \\ Moi University/School of Information Sciences, Eldoret, Kenya \\ E-mail: jkmutai@gmail.com \\ Bii K. Harrison and Kiplang'at N. Joseph \\ University of Kabianga/School of Information Science and Knowledge Management, Kericho, Kenya \\ E-mail: jhkbii@gmail.com \\ Technical University of Kenya/Department of Information and Knowledge Management, Nairobi, Kenya \\ E-mail: jkngetich@yahoo.co.uk
}

\begin{abstract}
The purpose of this work is to enhance the life insurance underwriting process by building a knowledgebased system for life insurance underwriting. The knowledge-based system would be useful for organizations, which want to serve their clients better, promote expertise capture, retention, and reuse in the organization. The paper identifies the main input factors and output decisions that life insurance practitioners considered and made on a daily basis. Life underwriting knowledge was extracted through interviews in a leading insurance company in Kenya. The knowledge is incorporated into a knowledge-based system prototype designed and implemented, built to demonstrate the potential of this technology in life insurance industry. Unified modelling language and visual prolog language was used in the design and development of the prototype respectively. The system's knowledge base was populated with sample knowledge obtained from the life insurance company and results were generated to illustrate how the system is expected to function.
\end{abstract}

Index Terms - Life insurance, underwriting, Knowledge management, Knowledge engineering, Knowledge-based system.

\section{INTRODUCTION}

A Knowledge-Based System (KBS) can be described as an interactive, computer-based system designed to represent and reason with knowledge of some specialist subject with a view to solving problems and/or giving advice using a combination of rules, analytical techniques and knowledge retrieval. Such systems help develop and evaluate appropriate alternative and pass a verdict based on the best alternative.

Knowledge-based systems should focus more on enhancing and expediting the life underwriting process and on promoting the retention and reuse of expertise in an organization rather than eliminating or replacing experts in life insurance underwriting. It is in this light that a decision was made to develop a knowledge-based system to enhance the life insurance underwriting process.
Life insurance underwriting is a complex and slow process due to many factors taken into consideration. It relies on scarce, often expensive-to-hire human experts to assess and communicate the verdict on life insurance proposals. This, in the end, may impede the provision of quality service delivery to clients and put the organization under the constant threat of globally losing its core life underwriting expertise to competitors. In these cases, a knowledge-based system can be very valuable in capturing, reusing, and retaining the expertise in the organization in addition to expediting and improving the quality of services provided. The objective of knowledge management systems is to support creation, transfer and application of knowledge in organizations [1].

The objective of this study was to analyze the life insurance underwriting process and identify models to support the process and to design and implement a knowledge-based system using a rule-based approach to satisfy the needs of the life insurance industry.

The rest of this paper is organized as follows: Section 2 includes the literature studies related to customer risks, life insurance and knowledge engineering. Whereas, Section 3 gives the materials and methods used in the study. Section 4 gives an analysis of results obtained while section 5 gives a full description of the models and designs of the knowledge-based system including system inputs and outputs. Conclusions and future work are given in section 6 .

\section{RELATED WORKS}

This section is organized into two major themes, which are customer risks and life insurance, detailing how risks are determined in life insurance underwriting, and knowledge engineering process, documenting how a $\mathrm{KBS}$ is developed

\section{A. Customer Risks and Life Insurance}

Frank and Keith [2] define risk as the uncertainty of future outcome. Risks cannot be avoided completely but a means to deal with them is put in place. The chance of risks occurring in the lives of persons and their property 
can be considerably reduced by good management and sensible planning [3]. This can be achieved through the processes of risk management.

According to Yeats and Cadle [4], the essentials of risk management include the establishment of mechanisms to keep risks under review by identifying the potential risks to the individual or property. The assessment of the likelihood of each risk materializing is done, and an assessment of the probable impact of each risk is determined. Finally, measures to avoid each risks occurring is formulated.

Life insurance is a contract under which the insurer in consideration of a premium paid either in lump sum or by monthly, quarterly, half yearly or yearly installments undertakes to pay a fixed sum of money on the death of the insured or on the expiry of a specified period of time whichever is earlier [5].

Insurance is a means of spreading risks and involves pooling of risks by a group of people who are subject to an insurable risk, contributing regularly to a fund, and the fund so created is utilized to compensate those unfortunate few members of the group who actually suffer a loss due to some unexpected calamity [5]. This way, all members on an equitable basis share the loss of a few. It is a social device for pooling and dividing risks among a large number of persons. Insurance is the sharing of the loss of the few by the many [3].

\section{B. Knowledge Engineering}

Negnevitsky [6] defines knowledge engineering as the process of building a KBS with six main steps, namely the assessment of the problem, acquiring data and knowledge, developing a prototype, development of a complete system, evaluation and revision of the system and finally the integration and maintenance of the system. However, in order to achieve the full benefits of a KBS, Turban [7] proposes five process activities in knowledge engineering and the interrelationships among them (Fig. 1). The knowledge acquisition process is the first step that involves the acquisition of knowledge from the experts, books documents or computer files. The knowledge may be specific to the problem domain and the problem solving procedures, or it may be general knowledge. The second step is knowledge validation process involving verification of the expertise using test cases until its quality is acceptable. The third step is the knowledge representation process, which involves the encoding of the knowledge in the knowledge base. The fourth process is inference, involving the design of software that enable a computer to make inferences based on the knowledge and then provide advice to the user on specific issues. The last step is the explanation and justification involving the design and programming of an explanation capability, such as the ability to answer questions like why the computer needs a specific piece of information or how the computer derived a certain conclusion.

Knowledge engineering is a good example of managing knowledge in an organization since it creates, distributes, and maintains knowledge in an organization.
Wijnhoven [8] defines knowledge management as the process that creates, distributes, uses, exploits, and maintains knowledge. These processes are very essential in exploitation of life insurance expertise in order to maintain the knowledge and to avoid its loss due to the loss of its experts.

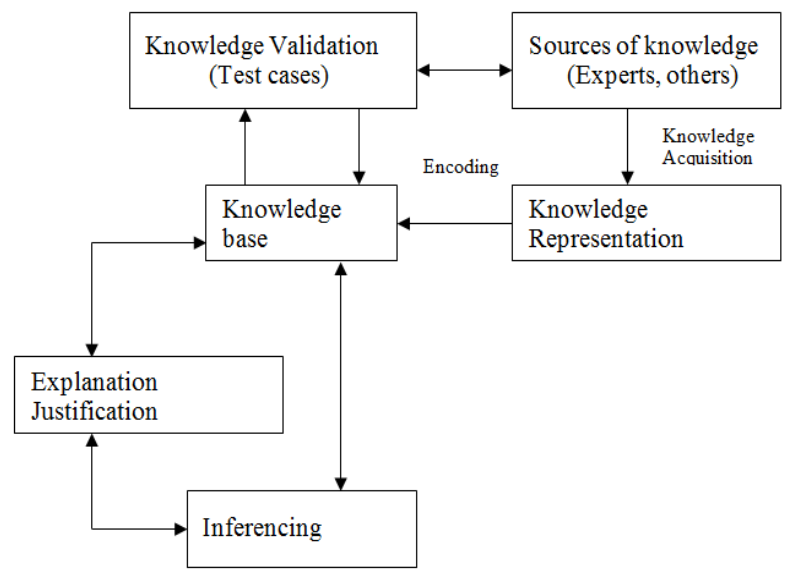

Fig.1. Knowledge Engineering process. Source: [7]

\section{MATERIALS AND METHODS}

This study adopted the qualitative research approach since the targeted data was in form of words, ideas, and explanations. Walliman [9] explains that qualitative research is to do with people and their activities, and is concerned with variables that cannot be quantified. More often, the data are in a form of words rather than numbers.

The study selected a leading life insurance company in Kenya as a case study. A case study was more appropriate since knowledge is unique to an organization.

Interviews were used to gather data and the study did not take a sample since the entire population of 23 members was perceived to be small. According to Creswell [10], interviews are useful when participants cannot be observed directly The researchers aimed at a census until saturation point was achieved.

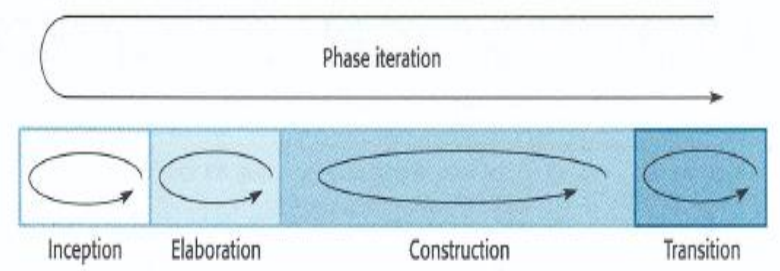

Fig.2. Phases in the Rational Unified Process. Source: [10]

The rational unified process (RUP) was followed in developing the system. According to Sommervile [11], the RUP is a modern hybrid process model that brings together elements from all of the generic process models, which are the waterfall model, the evolutionary development and the component-based software 
engineering process model. The phases in the RUP (Fig. 2) are more closely related to business rather than technical concerns [11].

The RUP is made up of four phases which are: Inception; elaboration; construction and transition. The goal of the inception phase is to establish a business case for the system. All external entities that interact with the system are identified and defined. The elaboration phase is concerned with developing an understanding of the problem domain and establishing an architectural framework for the system. The construction phase is essentially concerned with system design, programming and testing where parts of the system are developed and intergrated. The transition phase is the final phase concerned with the deployment of the system from developers to the users. Iteration within the RUP is supported in two ways: each phase may be enacted in an iterative way with the results developed incrementally or the whole set of phases may also be enacted incrementally [11].

\section{RESULTS}

The study analyzed the processes and tasks in life underwriting, in order to clarify what was necessary for the development of the KBS. The task of a knowledge engineer at the analysis level is to discover essential principles of the domain by abstraction from a mass of information gleaned from experts to create an outline to guide in the development of the knowledge-based system [12]. This section is organized into two themes: risk assessment and determination, and variables (Input and output) in the underwriting process.

\section{A. Risk assessment and determination}

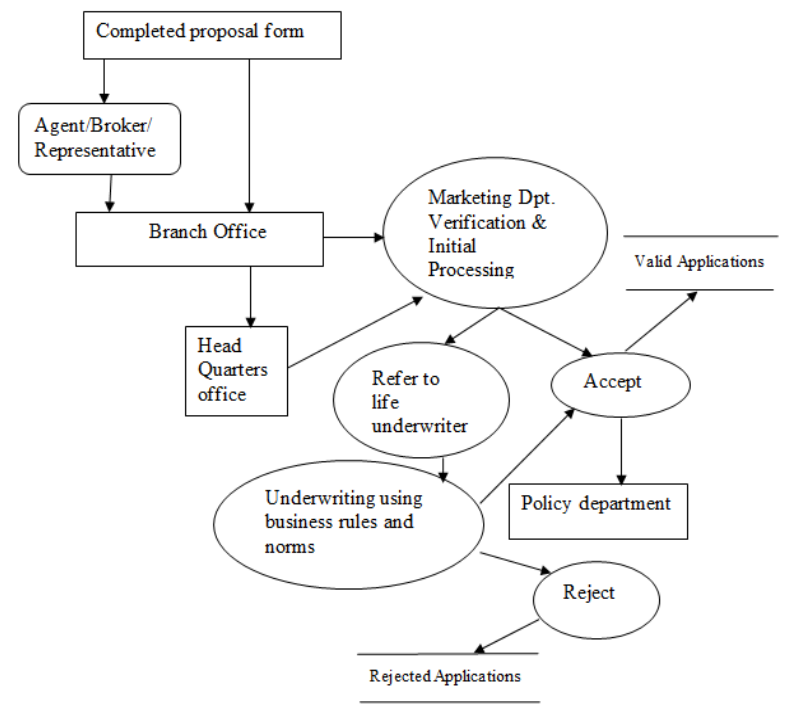

Fig.3. Application and acceptance process of life insurance applications

In life insurance business, the first step taken by potential clients is filling a proposal form and in the second step, the forms are forwarded for further verification and simple initial processing. The third and the last stage involve specialist underwriters who assess the applications based on the applicable rules and norms (Fig. 3).

\section{B. Variables in the underwriting process}

Life insurance underwriters took into consideration factors including age, occupation, medical history and perceived current state of health of an individual, in ascertaining the risk profile of an individual proposed for life cover. These factors are used to determine the risk of early death of an individual proposed for life cover. If the risks posed (as perceived by life underwriters) were acceptable, the insurance company accepted the application and if the risks were unacceptable, the application was declined. These factors were considered as inputs in the underwriting process as shown in fig. 4 .

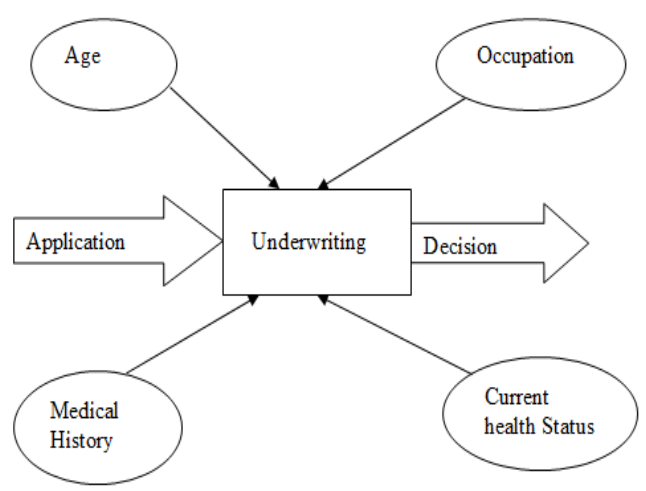

Fig.4. Input variables in the underwriting process

Age was considered as an important factor in ascertaining the risk of death of an individual proposed for life cover. Older people were perceived to have shorter lifespan (expectancy) while younger people had longer life span. This meant that, if other factors that contributed to death were held constant, the older an individual was the higher the risk of death and the younger an individual was, the lower the risk of death. Table 1 summarizes the age category of individuals as perceived by life underwriters and the perceived risk profile associated with it.

Table 1. Age risk table

\begin{tabular}{|c|c|c|}
\hline Age Category & Age Classification & Perceived Risk \\
\hline Below 46 yrs. & Young to middle age & Low risk \\
\hline $46-60$ yrs. & Old & Average to high risk \\
\hline Over 60 years & Very old & Very high risk \\
\hline
\end{tabular}

Experts used the identified age risk factor together with other factors to estimate the risk of early death by an individual proposed for life cover.

Occupation, what an individual engaged in, daily as a profession, career, sport or hobby was a factor taken into consideration in estimating the risk of early death of an individual proposed for life insurance. Some occupations were considered more risky and dangerous than others were and that the higher the risk associated with an occupation the higher the perceived risk of early death. This meant that if other factors that contributed to death 
of persons were held constant, an individual who engaged in non-hazardous activities as an occupation was likely to live longer than a person who engaged in hazardous activities as an occupation. Table 2 summarizes the risks associated with the different classes of occupations identified by the researchers.

Table 2. Occupational risk table

\begin{tabular}{|c|c|c|}
\hline $\begin{array}{c}\text { Occupation } \\
\text { Class }\end{array}$ & Occupation Category & Perceived Risk \\
\hline Class I & Office work & Low Risk \\
\hline Class II & Supervisory & Low Risk \\
\hline Class III & Manual work & Average to High Risk \\
\hline Class IV & Hazardous work & Very High Risk \\
\hline
\end{tabular}

Medical history of a person proposed for life cover, was highly considered in determining the risk of early death. The medical history questionnaire helped the underwriters check and detect applicant's pre-existing medical conditions before a life cover. The presence of pre-existing conditions, for example, diabetes, hypertension, asthma and other chronic illnesses led to a perceived high risk of early death. In addition, the experts used the proposal forms to gather information that helped the underwriters estimate the probability of perceived increase or decrease in the risk of death based on family health history as shown in table 3 .

Table 3. Medical history risk table

\begin{tabular}{|c|c|c|}
\hline Medical History & $\begin{array}{c}\text { Perceived } \\
\text { Situation }\end{array}$ & Risk profile \\
\hline No existing medical condition(s) & Good & Low risk \\
\hline No hereditary disease(s) in family & Good & Low risk \\
\hline Existing medical condition(s) & Bad & High risk \\
\hline $\begin{array}{c}\text { Presence of hereditary disease(s) } \\
\text { in family }\end{array}$ & Bad & High risk \\
\hline $\begin{array}{c}\text { Presence of existing medical } \\
\text { condition(s) \& hereditary } \\
\text { disease(s) in family }\end{array}$ & Very bad & Very high risk \\
\hline
\end{tabular}

Table 4. Smoking/Alcohol consumption risk table

\begin{tabular}{|c|c|c|}
\hline Status & $\begin{array}{c}\text { Perceived Health } \\
\text { Condition }\end{array}$ & Risk Profile \\
\hline Non smoker & Good & Low Risk \\
\hline Non-alcohol consumer & Good & Low Risk \\
\hline Smoker & Bad & High Risk \\
\hline Alcohol Consumer & Bad & High risk \\
\hline $\begin{array}{c}\text { Both smoker and } \\
\text { alcohol consumer }\end{array}$ & Very bad & Very high risk \\
\hline
\end{tabular}

The current health status of an individual proposed for cover emerged as another important factor considered in life underwriting. Perceived current state of health of an individual was a possible risk of death. Life underwriters assessed this by carefully examining an individual's medical history form and in relation to unhealthy personal habits, the proposed individual engaged in, mainly smoking and alcohol consumption, as well as attributes such as the weight and the height of the individual. Table 4 summarizes the perceived risks posed by an individual's personal habits.

Non-smokers and non-consumers of alcohol were perceived to be of better health and therefore posed a minimal risk of death as compared to smokers and consumers of alcohol who were perceived to be of poor health and therefore stood a higher risk of death. In addition, if the individual proposed for life cover was both a smoker and consumer of alcohol, the perceived risk of death increased. It could therefore be rightly concluded that non-smokers and non-consumers of alcohol lived longer than smokers and consumers of alcohol, if other factors that contributed to death were assumed constant.

The body mass index (BMI), that is, the ratio of the weight to the height was a direct indicator of the risk of developing life style diseases, for instance, diabetes or high blood pressure that increased the risk of death. This therefore informed the decisions life underwriters made on the proposals for life cover as shown in table 5 .

Table 5. Body Mass Index risk table

\begin{tabular}{|c|c|c|}
\hline BMI & Condition & Health Risk \\
\hline Less than 19 & Underweight & High risk \\
\hline Between 19-24 & Normal & Minimal(low) risk \\
\hline Greater than 24 & Overweight & High risk \\
\hline
\end{tabular}

From table 5, we learn that if the ratio of weight to height of a person was 18 or below, the person was considered underweight and it carried a high risk of disease or sickness. If the ratio was between 19 and 24, then it was considered normal and it carried a minimal (low) risk. However, as the ratio increased over 24, the perceived risk of developing diseases increased. It was therefore apparent that the weight and the height of the individual proposed for life cover was important in approximating the risk of death of an individual.

Standard underwriting principles had four categories of risk classifications (Output variables) that underwriters used to summarize their analysis and to communicate their verdict concerning the risk profile of a proposed life insurance. These were:

- Preferred classification- a preferred classification was one with combined low risk and was charged with low premium.

- Standard classification - This was a classification with combined average risk and was charged with a standard (average) premium.

- Rated Classification- (also referred to as a substandard classification). This was a combined high-risk category charged with relatively high premium amounts.

- Declined classification- also referred to as uninsurable category, this was a classification of cumulatively extremely high risks in nature. The risks in this category were not acceptable for cover by the insurance company selected for this study. 


\section{Knowledge-BAsed System Modelling, Design AND DEVELOPMENT}

\section{A. Business Modelling}

Business modelling was concerned with the business processes in the domain of life insurance underwriting.
Context and activity models were developed. According to Sommerville [11], system context diagrams describe information and control flow between the system and its environment. A use case diagram (Fig. 5) was developed to show how the system interacts with its environment and to describe the direct organizational environment.

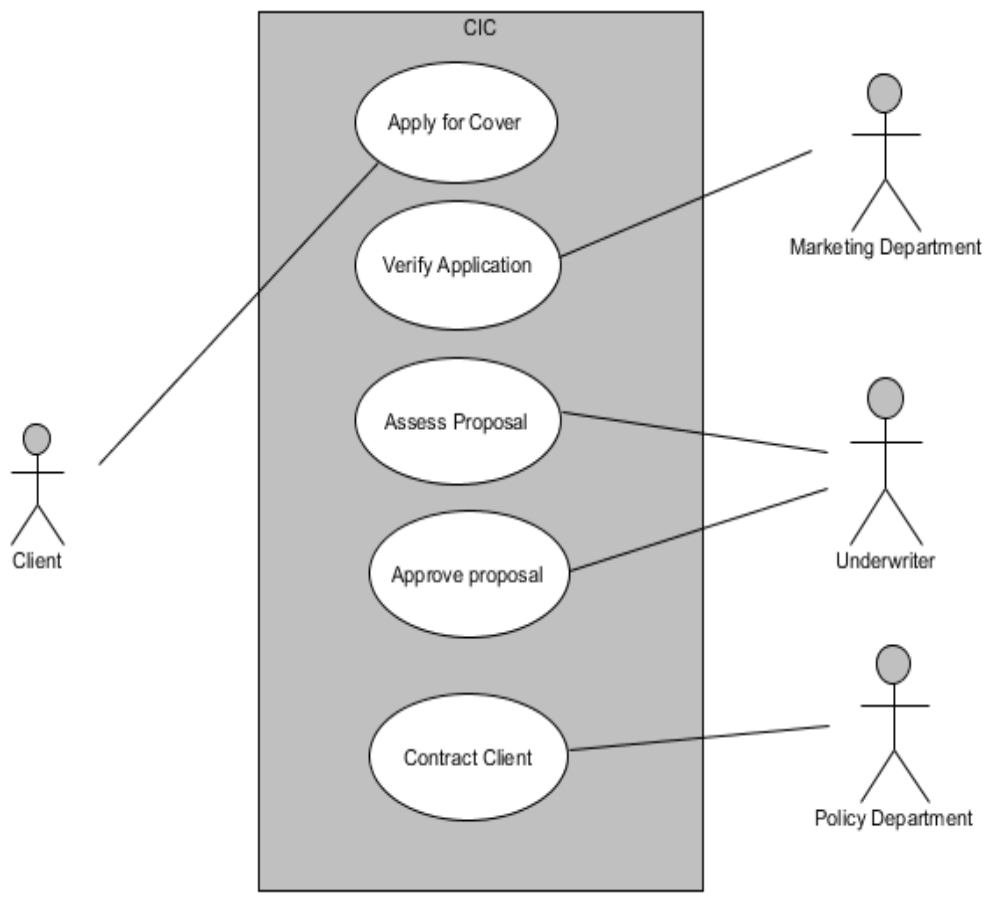

Fig.5. Use case diagram for life insurance application

The process of assessing a life insurance application against the domain applicable rules and norms is modelled in the activity diagram below (Fig. 6).

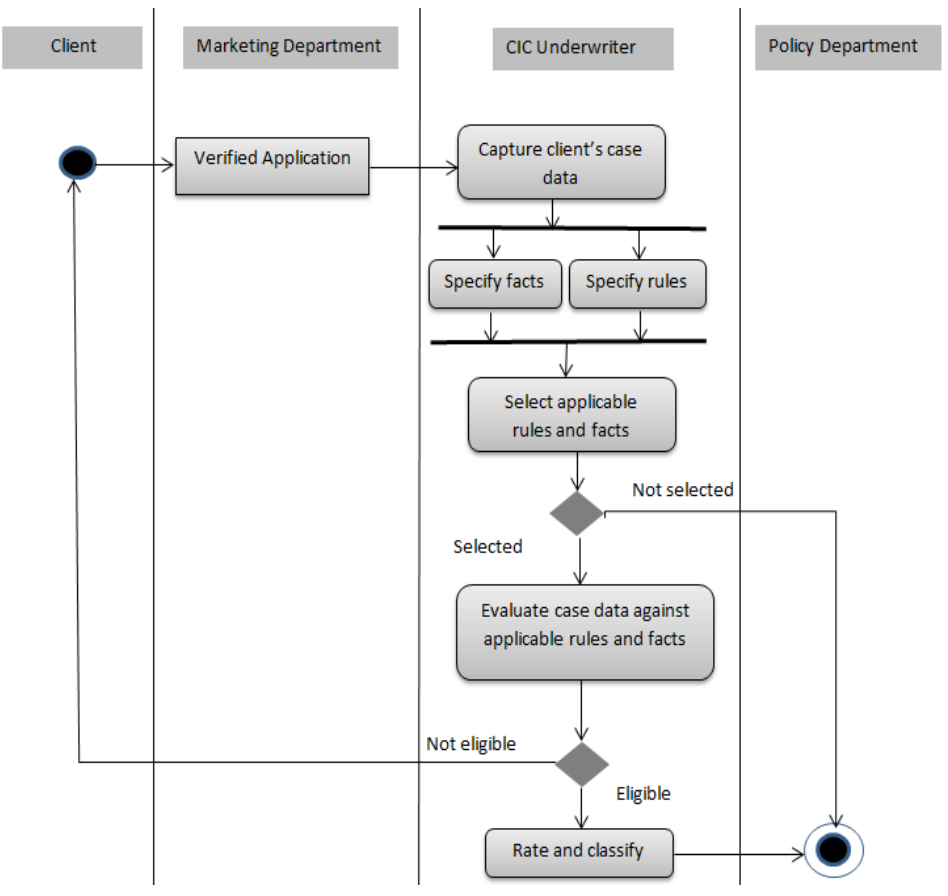

Fig.6. Activity diagram for life insurance application assessment 
The most commonly seen usage of activity diagrams is to model 'workflows' [13].

\section{B. Conceptual Modelling of domain knowledge}

Conceptual modelling for this study was concerned with clarifying the structure of life insurance underwriting task using modelling techniques. Hakansson [14] states that conceptual modelling is an important stage in the KBS development process, in that

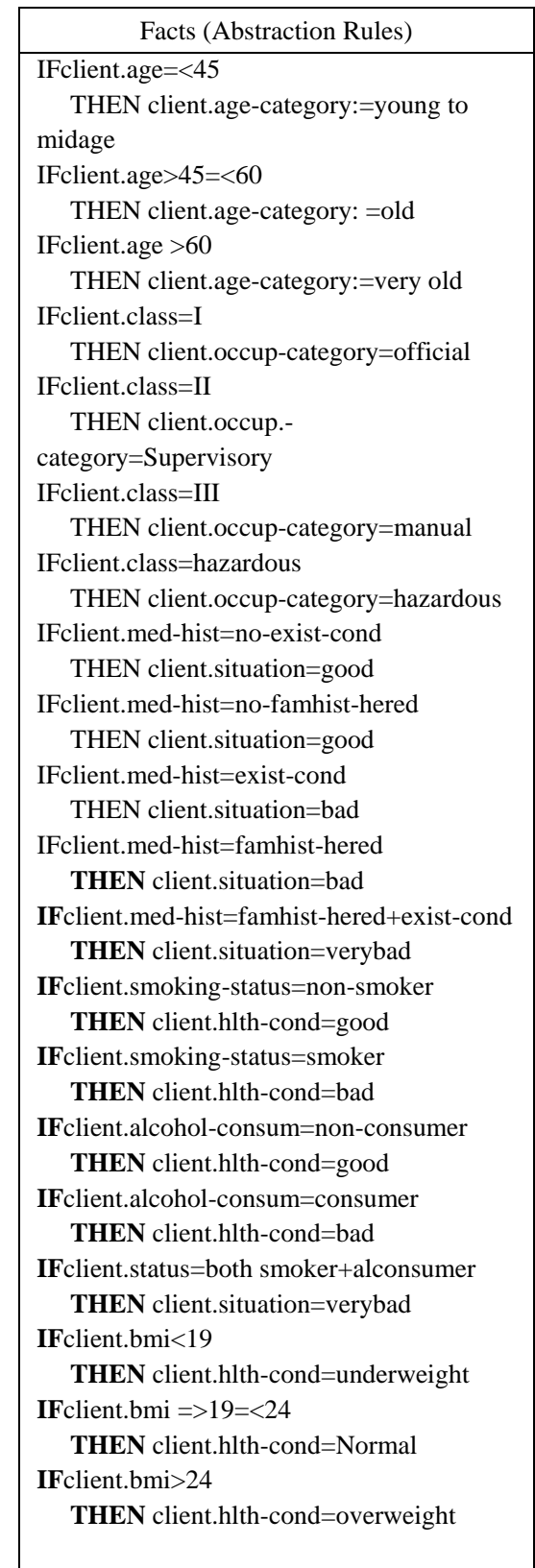

Fig.7a. Sample KBS Facts

The main purpose of these knowledge bases was to contain the sets of rules with similar purpose and/or structure that define the knowledge bases. They comprised of the abstraction rules containing the facts in it clarifies the structure of a knowledge-intensive business task. Modelling of life insurance underwriting domain knowledge was done to capture the structure of information and knowledge types in life insurance underwriting process [15]. Three types of knowledge bases were defined and modelled (Fig. 7a, Fig. 7b and Fig. 7c).

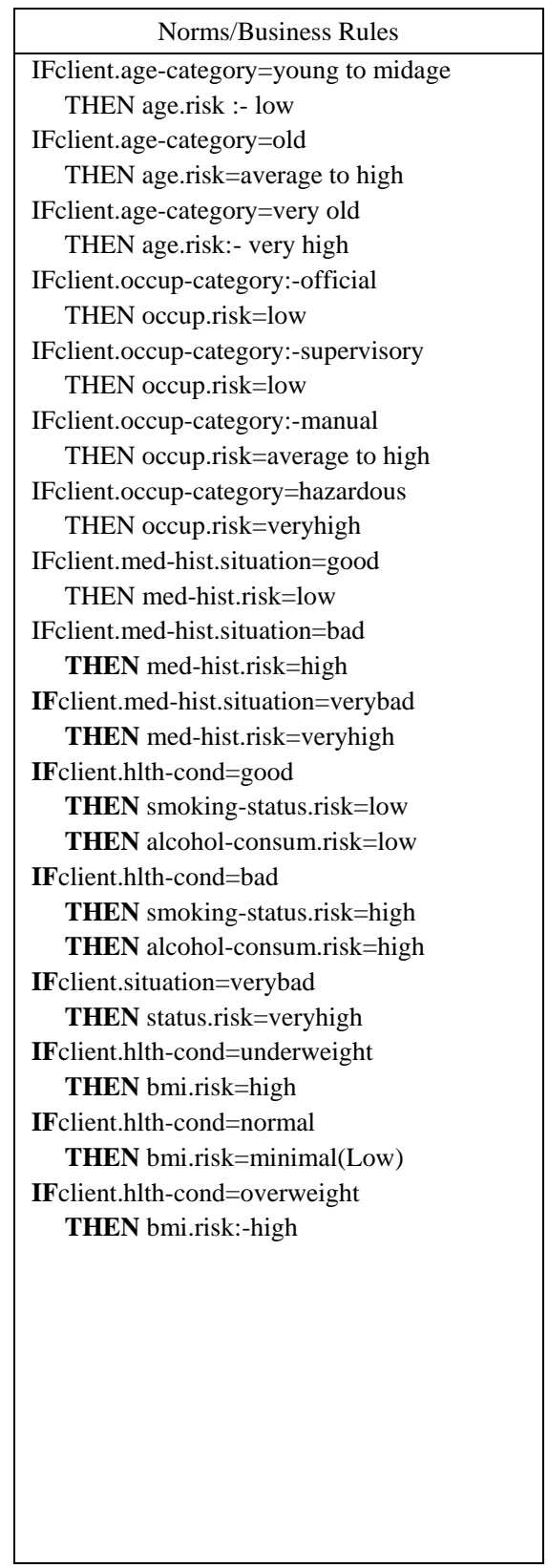

Fig.7b. Sample KBS Business rules

life insurance underwriting domain, the business rules containing the applicable norms in life insurance underwriting. Decision rules showing how decisions are arrived at in the KBS was modelled. (Fig. 7c). 


\begin{tabular}{|c|c|}
\hline \multicolumn{2}{|l|}{ DECISION TABLE1 } \\
\hline \multirow[b]{2}{*}{ CONDITIONS } & ALTERNATIVE CASES \\
\hline & 12345567891011121314151617181920 \\
\hline Age greater than 45 & NNNNNNNNN N N N N N N N N N N \\
\hline Occupation not official or supervisory & N N N N N N N N N N N N N N N N N N N N \\
\hline Existing medical condition & $Y Y Y Y Y Y Y Y \quad Y \quad Y Y Y Y \quad Y \quad Y \quad Y \quad Y \quad Y \quad Y \quad N \quad N \quad N \quad N$ \\
\hline Hereditary condition in family present & $Y Y Y Y Y Y Y Y N N N N N N N N \quad Y \quad Y \quad Y \quad Y$ \\
\hline Smoker & 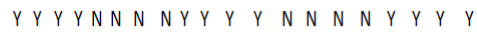 \\
\hline Consumer of alcohol & Y Y N N N Y Y $\quad N \quad N \quad Y Y Y \quad N \quad N \quad Y \quad Y \quad N \quad N \quad Y \quad Y \quad N \quad N$ \\
\hline BMI not between 19 and 24 & 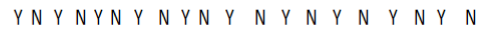 \\
\hline \multicolumn{2}{|l|}{ ACTIONS } \\
\hline Preferred( low risk) & $\mathrm{X}$ \\
\hline Standard (Average risk) & 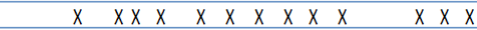 \\
\hline Rated (High risk) & $x \times x \quad x \quad x$ \\
\hline Declined (Very high risk) & \\
\hline
\end{tabular}

Fig.7c. Sample Decision table

Fig. 7c above shows a sample decision table containing the inference of facts (Fig. 7a) against business rules (Fig. 7b) in life underwriting domain. This shows how the KBS arrived at its decision based on an individual case data provided.

\section{Conceptual Modelling of Task/Inference Knowledge}

An activity diagram was developed to model a decision taken based on the assessment of a case provided against specified norms/criteria in life insurance underwriting, as shown in fig. 8.

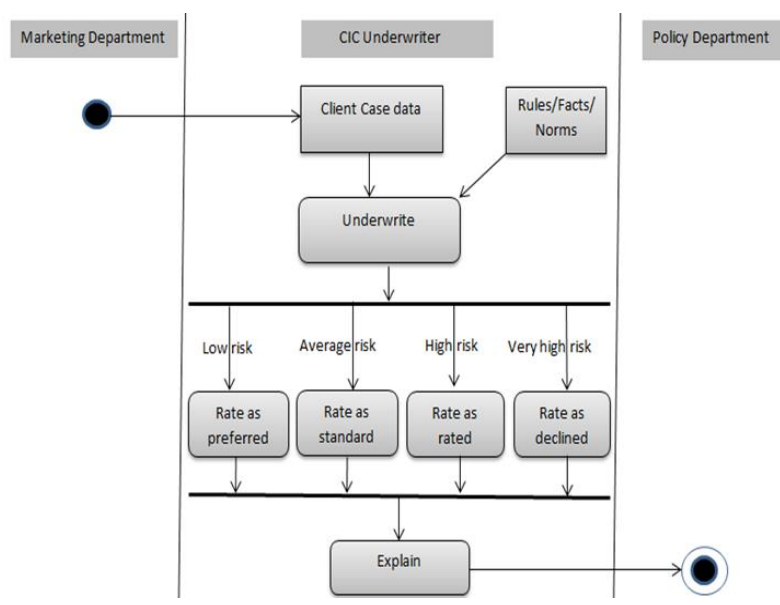

Fig.8. Activity diagram for life insurance underwriting

The goal of an assessment task in life insurance underwriting domain is to assess a particular case presented, against life insurance underwriting norms and to categorize an application either as preferred, standard, rated or declined. Thereafter, an explanation is provided to support the decisions arrived at (Fig. 8).

\section{Knowledge-based system design}

A structural framework (architectural design) showing the major components of the KBS was developed as shown in the block diagram below (Fig. 9).

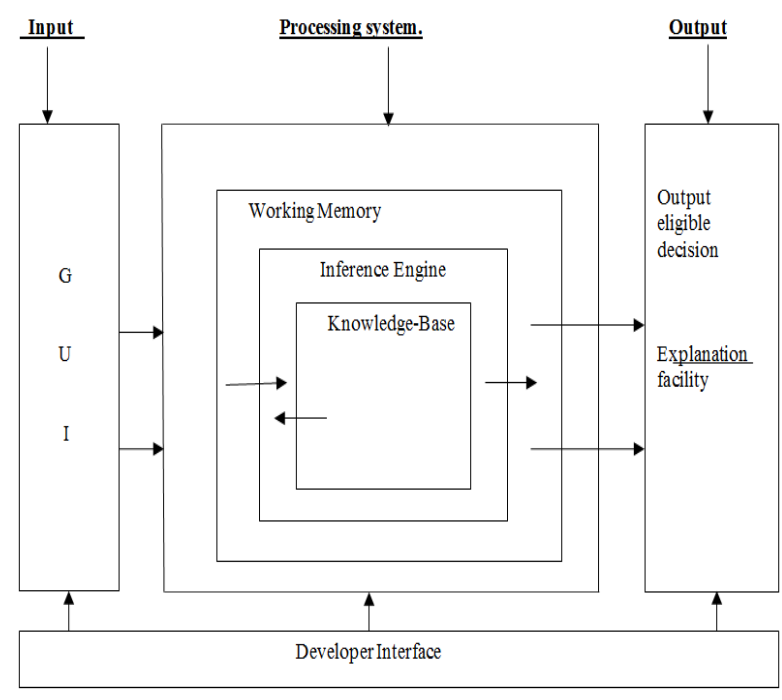

Fig.9. Proposed knowledge-based life insurance underwriting system

The KBS is structured into three main components: The input, the processing system and the output system. The sequence of activities, communications and interactions between the components of the KBS are modelled in the sequence diagram below (Fig. 10).

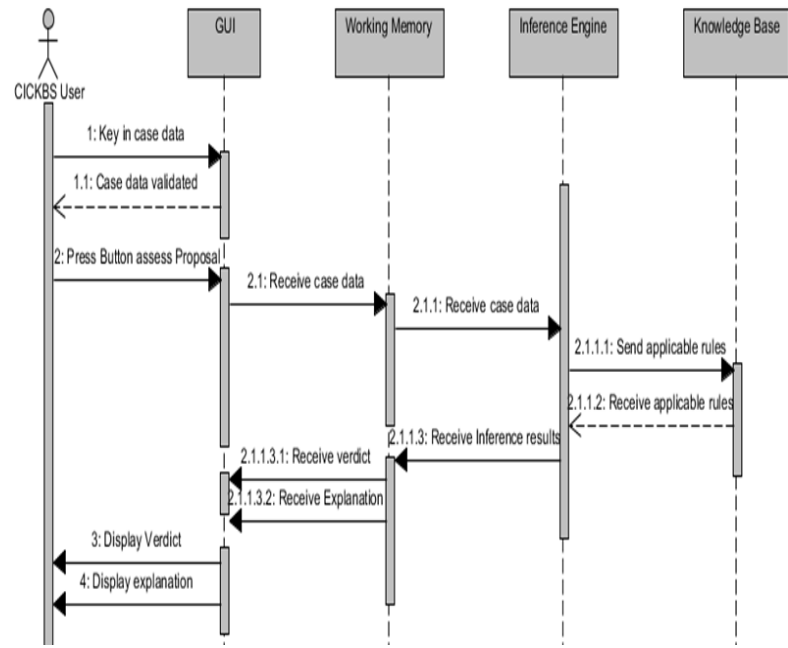

Fig.10. KBS Sequence diagram for life underwriting process

The KBS input and output interfaces were designed and developed with the user in mind. Simplicity, user friendliness, ease of use and consistency of command buttons and menu driven applications were considered and used. The inputs and outputs are through forms and dialogues on the screen respectively, which are similar in format and structure to maintain consistency.

The knowledge base, which holds knowledge in an abstract form, was designed. When a specific problem is presented to the $\mathrm{KBS}$, only the relevant knowledge is called from the knowledge base.

A class diagram showing how entities in the knowledge base relate with one another was developed (Fig. 11). 


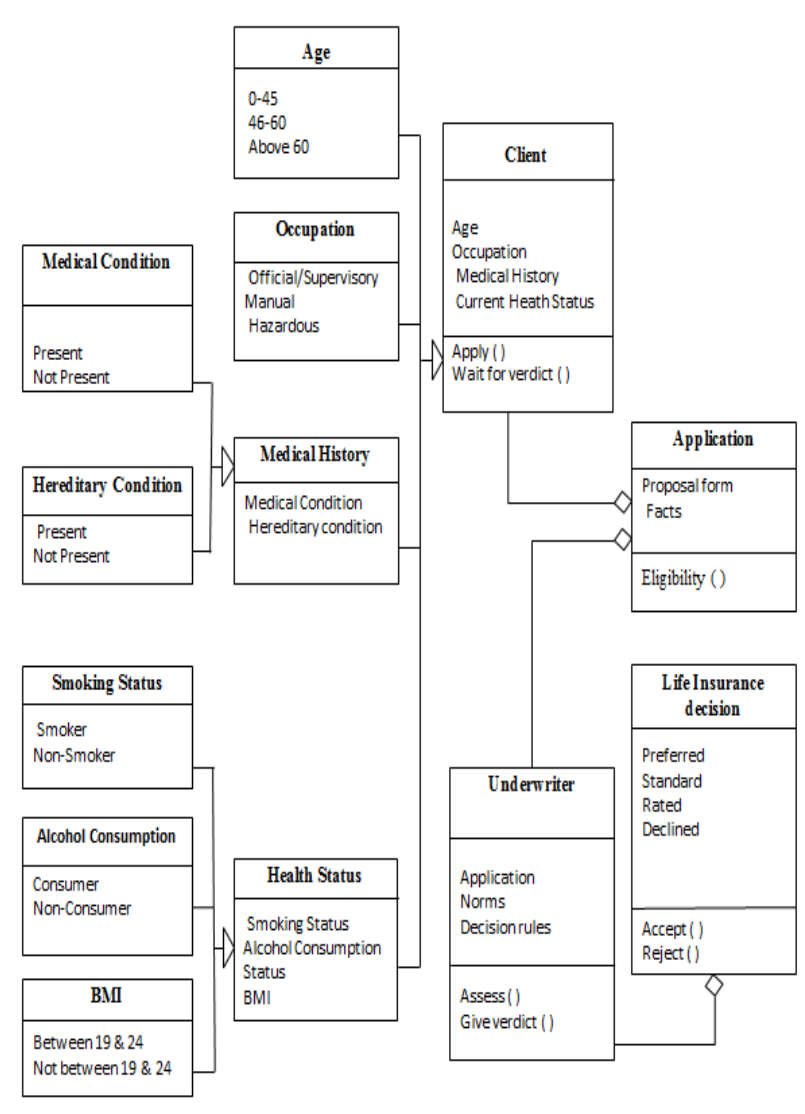

Fig.11. KBS Entity relationships class diagram

The four main classes in life insurance underwriting i.e. the client, the application, the underwriter and the life insurance decision and the relationships between them are shown in fig. 11 above. The figure also shows the actions that can be performed at each class level, for instance, a client applies and waits for a verdict and the underwriter assesses and gives a verdict to an application.

The KBS was programmed using the visual prolog 7.4, personal edition.

\section{E. Rules in the knowledge-based system}

Decision rules in the knowledge base were organized using IF-THEN rules structure. The general form of the rules is shown in the example below:

IF client.age $=<45$ AND

Occupation $=$ official OR supervisoryAND

Med-hist=no-exist-cond OR

Med-hist=no-famhist-hered AND

Smoking-status=non-smoker AND

Alcohol-consum=non-consumer AND

$\mathrm{Bmi}=$ between 19 and 24

THEN client.overalrisk=low

THEN risk.classification $=$ preferred

Rules in the decision tables were categorized as preferred, standard, rated or declined, in line with the output classification

A sample code for the above rule in the KBS is shown below.
/***Decision Table Preferred category***/

clauses

assessment ("The proposal is highly Prefered for life insurance since it has no risk factor associated with it"):factor ("below46yrs_ctl"), factor ("official_ctl"),

factor("noexmedcond_ctl"),factor("nohercondinfam_ctl") ,factor("nonsmoker_ctl"),factor("nonalcoholconsumer_ct l"),factor("between19and24_ctl"),!

\section{F. Building the user interface}

The user interface is the main point from which the KBS captures an input from the user and communicates its output to the user.

The above rule is captured in a typical transaction in the KBS as shown in the graphical user interfaces (screenshots) outlined below (Fig. 12, Fig. 13, Fig. 14 and Fig. 15).

i. Graphical user interface start up screen

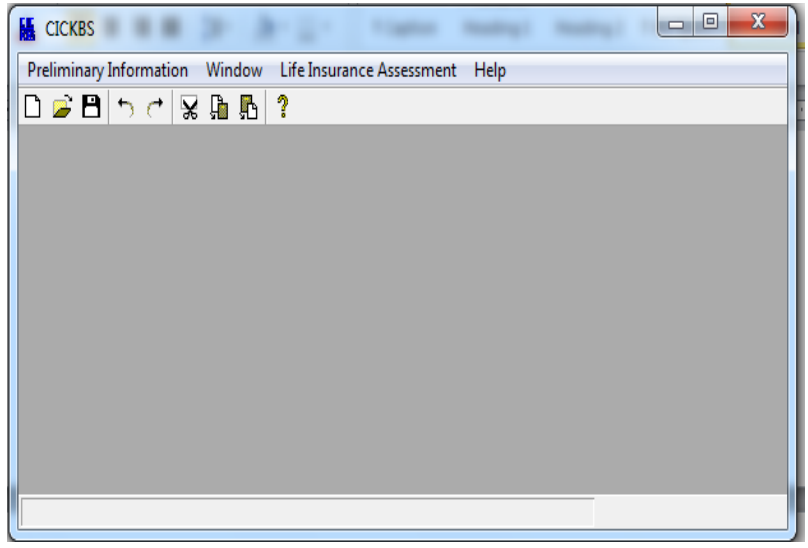

Fig.12. GUI start up window

ii. To assess a given life insurance proposal, a menu item 'Life insurance assessment' as shown by arrow $\mathrm{A}$ is clicked and the submenu 'new life proposal' is selected as shown by arrow B (Fig. 13).

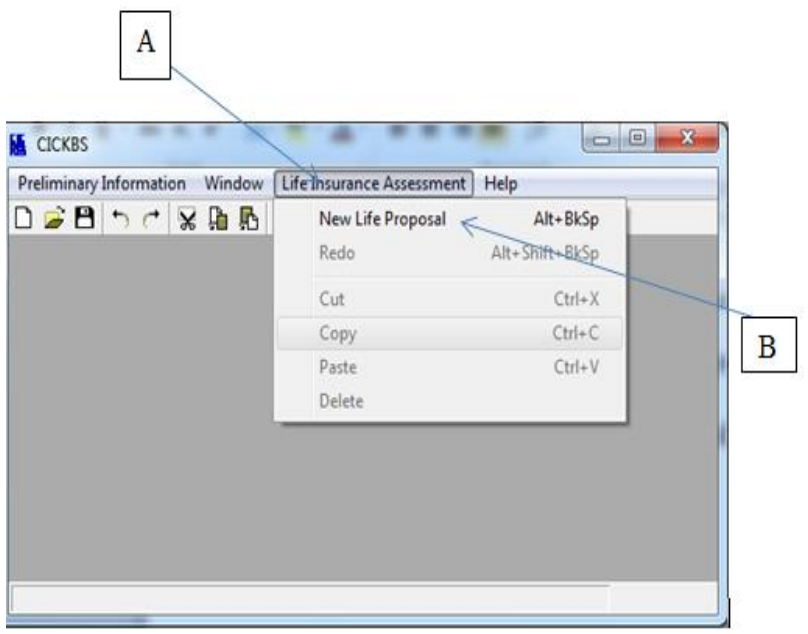

Fig.13. Main menu items selection window 
iii. When the submenu item as shown by arrow B in fig. 13 is selected, a new life proposal form appears (Fig. 14).

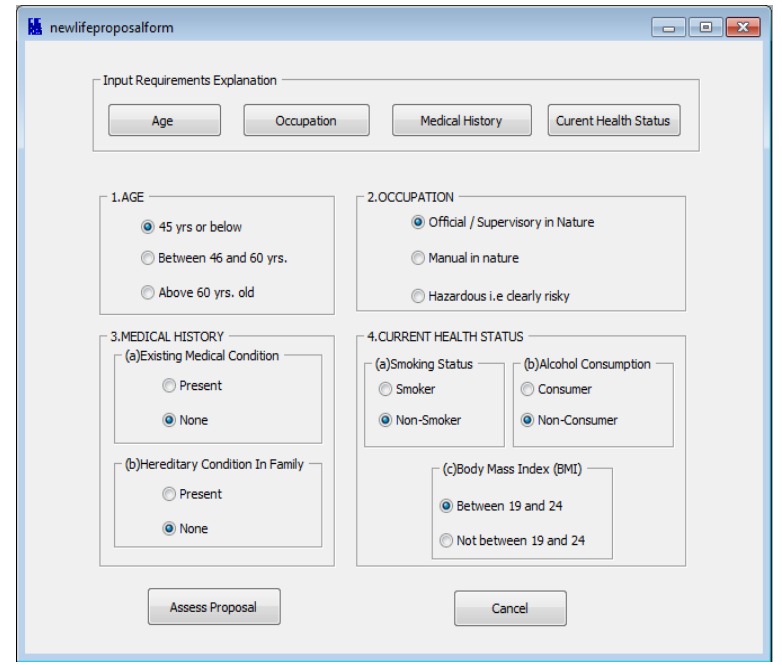

Fig.14. New life proposal form

iv. The user clicks the radio buttons depending on the particular case provided (e.g., the above rule is shown in the form (Fig. 14).

v. The user finally clicks the button 'Assess Proposal' and receives a response as shown in fig. 15 .

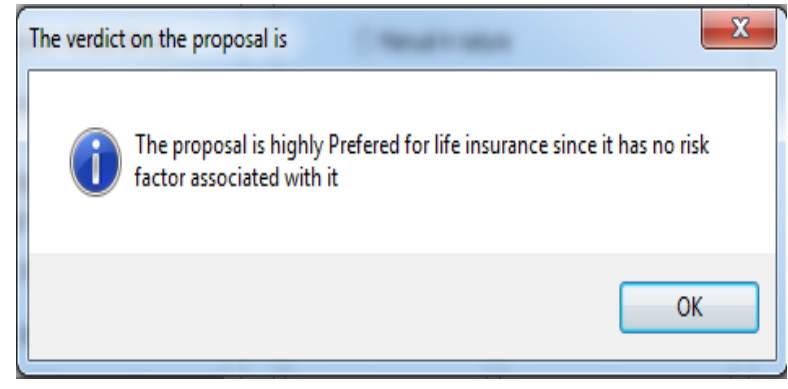

Fig.15. Sample response screen capture

Based on the parameters set in the system it is expected to analyze and pass a verdict on other rules as captured in the system.

\section{G. Inference engine and the explanation facility}

The KBS developed uses a forward chaining inference mechanism whereby the user provides information about the problem to be solved and the KBS infers from the knowledge base by examining the facts in the knowledge base and giving a verdict together with its explanation. Forward chaining starts with data (data driven) and works towards conclusions.

Fig. 16 below shows a sample inference code in the knowledge base together with the explanation facility.

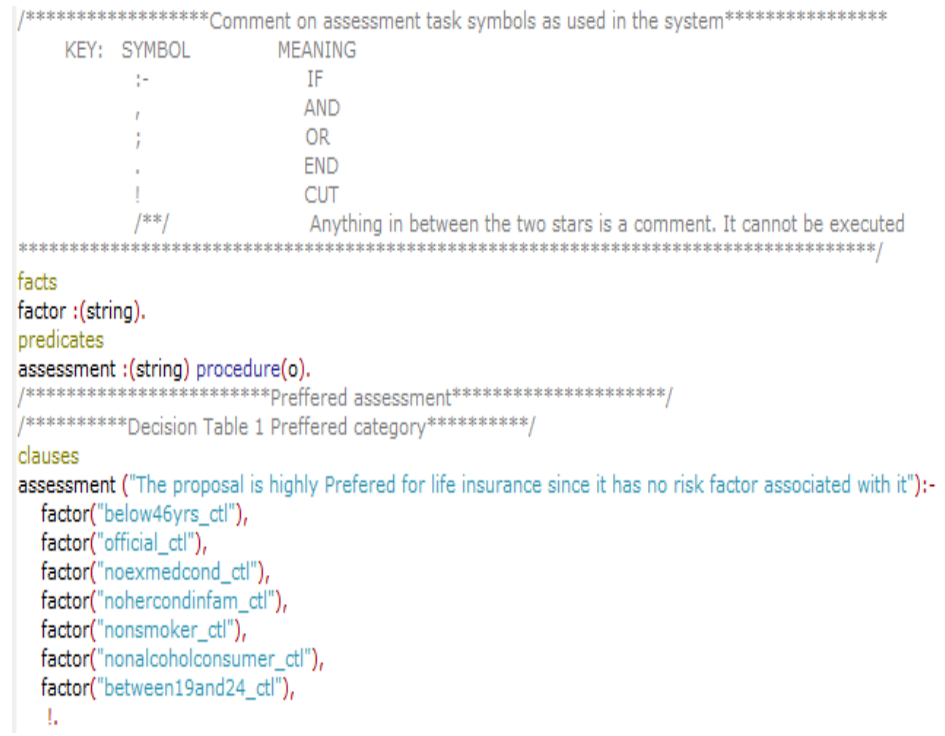

Fig.16. Sample Inference of facts code

\section{CONCLUSION AND FUTURE WORK}

In this paper, we proposed a knowledge-based system approach to enhance the life insurance underwriting process by expediting and computerizing the process. The paper identifies the main input factors and output decisions considered and/or made on a daily basis. Knowledge was extracted from experts and organized in the knowledge base using a rule-based approach in a manner that is maintainable and reusable in the organization. Visual prolog programming language was used to design and implemented the KBS. The knowledge base was populated using data from a leading live insurance company in Kenya.

Rules have been used to represent knowledge in the KBS. However, rules are known to perform poorly in highly uncertain situations. Therefore, future research could examine how Fuzzy logic could be used to address the limitations of rules in developing knowledge-based systems for life underwriting.

Finally, the study focused on developing the rules for 
the knowledge base and did not focus on storage of data captured and decisions of the KBS. Further work should integrate computer based knowledge management systems with database management systems in order to improve the aspect of information and knowledge management as a whole.

\section{REFERENCES}

[1] Alavi, M. \& leidner, D. E. (2001). Knowledge Management and Knowledge Management Systems, MIS Quarterly, 25 (1), 107-136.

[2] Reilly Frank, k. \& Brown Keith, C. (2011). Investment Analysis and portfolio Management $\left(10^{\text {th }}\right.$ ed.). USA: Cengage learning.

[3] Turner, D.E. \& Turner P.H. (1994). Business Management Studies. Malaysia: McMillan.

[4] Yeates D. \& Cadle James (2007). Project Management for Information Systems ( $5^{\text {th }}$ ed.). UK: Prentice Hall.

[5] Saleemi, N. A (2007). Storekeeping and stock control Simplified. Nairobi: Saleemi Publications Limited.

[6] Negnevitsky, M. (2011). Artificial Intelligence: A guide to Intelligent Systems. ( $3^{\text {rd }}$ ed.). Canada: Pearson Education Limited.

[7] Turban E. (1992), Expert systems and Applied Artificial Intelligence, New York: Macmillan

[8] Wijnhoven, F. (2003). Operational Knowledge Management: Identification of Knowledge objects, operation Methods and Goals and means for the Support Fuction”. The Journal of operational Research Society, 54 (2), 196-203

[9] Walliman, N. (2011). Your Research Project ( $3^{\text {rd }}$ ed.) London: SAGE Publications Ltd.

[10] Creswell, J. (2013). Research Design: Qualitative, Quantitative and Mixed Methods Approaches $\left(4^{\text {th }}\right.$ ed.). USA: Sage Publications

[11] Sommerville, I. (2010). Software Engineering ( $9^{\text {th }}$ ed.). U.K. Addison Wesley.

[12] Neale, M. (2004). Modelling Expertise for knowledge Development. The Journal of the operational Research Society, 41(5), 447-459.

[13] Holt J. \& Perry, S. (2010). Modelling Enterprise Architectures (Let Professional Application Series). London: Institution of Engineering and Technology

[14] Hakansson, A. (2001). UML as an approach to Modelling Knowledge in Rule-based Systems. In proceedings of the $21^{\text {st }}$ SGES International Conference on Knowledge Based Systems and Applied Artificial Intelligence, Peterhouse College, Cambridge, UK.

[15] Kendal and Kendal (2008). Systems Analysis and Design ( $7^{\text {th }}$ ed.). India: Prentice Hall Dorling Kindersly pvt ltd.

\section{Authors' Profiles}

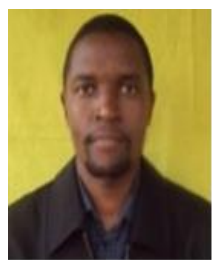

Mr. Mutai K. Joram Holds an MSc. In Information Technology from Moi University Kenya (2015) and a BBA. In Management Information Systems from Bugema University, Kampala (2006).He is a member of staff at the school of Information Sciences, Moi University Kenya. His research interests are in the areas of cyber security and audits, Artificial Intelligence, ICT
Governance and E-waste management. Mr. Mutai is a member of the ACM (Association for Computing Machinery) since 2014.

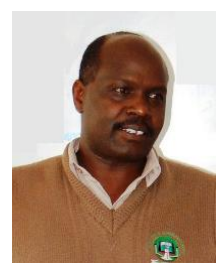

Dr. Bii K. Harrison is a senior lecturer and dean at the School of Information Science and Knowledge Management, University of Kabianga, Kenya. He holds a $\mathrm{PhD}$, in Management Science \& Engineering (Information Systems Management), from Wuhan, China (2009) and a Master of philosophy in Information Sciences (2001) in addition to a bachelor's degree in Information Sciences (Information and Media Technology) (1995) from Moi University, Kenya. His research Interests are in the areas of Information Systems Development process, social media in decision making and curriculum delivery, ICT in knowledge management and ICT management.

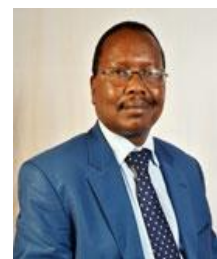

Prof. Kiplang'at N. Joseph Holds a PhD in library and Information Science form University of Zululand, South Africa (2004) and a Master of philosophy in Information Science (1995) in addition to BSc. In Information Science (1991) from Moi University, Kenya. He served in various capacities including lecturer, senior lecturer, associate professor and campus director at Moi University before his appointed as the deputy vice chancellor in charge of administration, planning and development at the technical University of Kenya, a post he currently holds.

How to cite this paper: Mutai K. Joram, Bii K. Harrison, Kiplang'at N. Joseph,"A Knowledge-Based System for Life Insurance Underwriting", International Journal of Information Technology and Computer Science (IJITCS), Vol.9, No.3, pp.40-49, 2017. DOI: 10.5815/ijitcs.2017.03.05 